\title{
A Fairer Face, a Fairer Tomorrow? A Review of Skin Lighteners
}

\author{
Levashni Naidoo *, Nokubonga Khoza * and Ncoza C. Dlova * \\ Department of Dermatology, Nelson R Mandela School of Medicine, University of KwaZulu-Natal, \\ 719 Umbilo Road, Durban 4001, South Africa \\ * Correspondence: levashni.naidoo@yahoo.com (L.N.); nokumas@yahoo.com (N.K.); \\ dlovan@ukzn.ac.za (N.C.D.)
}

Academic Editor: Johanna Maria Gillbro

Received: 7 May 2016; Accepted: 18 August 2016; Published: 7 September 2016

\begin{abstract}
From light-skinned deities depicted in ancient religious tableaux, pearl-swallowing practices in China, turmeric ceremonies in India to clay application in Africa, history has been coloured by our questionable aversion to the darker shades. Complexion has assumed psychological, economic and political currency with continued growth in the desire for skin lighteners sweeping the boundaries of country, race, cultural and socioeconomic status. This review explores our early associations with the symbolism of colour through religion, the ideals of complexion across cultures and time, the motivations behind the use of skin lightening practices, and the use of colour within political and economic agendas. Skin-lightening agents with regard to content, adverse effect profile and regulation are discussed and safe skin care practices in assisting with an individual's adoption of a more tolerable spectrum of shades are alluded to.
\end{abstract}

Keywords: skin-lighteners; skin bleaching; black skin; ethnic skin; history; culture; economics; motivations; ingredients; abuse; adverse effects

\section{Introduction}

The superficial practice of skin lightening represents a complex interplay of historical, cultural, social, psychological and political factors [1]. The allure of a more translucent complexion is alluded to by practices dating from Cleopatra's infamous milk baths to Queen Elizabeth I's application of ceruse and face powder [1,2]. While some may consider the practice of lightening a relic of a bygone era, the trend continues to thrive with use showing an increasing trend even amongst young, educated women [3,4]. It is intriguing to unravel the continued motivation for lightness. This article explores our early associations with colour, the voices that continue to guide the colour we feel we should be comfortable with, the motivations we own up to in the pursuit of an altered physical self, the spectrum of products we use in achieving this end and the fundamentals we need to grasp if we are to look toward a more tolerant, embracing spectrum of shades.

\section{Religion and the Association with Lightness}

The origins of symbolic dichotomy assigned to the colours black and white are interwoven with religious symbolism. Subliminal reinforcement of the superiority of whiteness through association with God or supreme beings is depicted through the portrayal of white-skinned goddesses and Buddha in China, light-skinned deities in India and the description of the first super humans as white in Shaman folklore in Korea [5].

In contrast to these "good", "pure" and "virtuous" associations with white skin, dark skin has been painted as a metaphor for being "wrong", "unfair" or "dirty" [6]. The dark-skinned Hindu 
goddess Kali channels her energy toward cruelty and destruction. If we think further across other religions, similar portrayals of colour become apparent.

\section{The Cultural Currency of Fairness: Across the Globe}

From religion to cultural practice, a key component of white skin as one of the hallmarks of virtue and personal beauty can be traced as far back as the first Korean Dynasty in the Gojosean Era (475BC-221BC) in their pursuit of "skin like white jade" [7], to Japan where the application of white face powder has been considered a woman's moral duty since the Edo period [8,9]. In China females were known to have swallowed crushed pearls in their pursuit of a milk-white complexion [10]. Across India, where the terms fair and beautiful are synonymous, white skin is considered a mark of caste and class, with turmeric powder being applied almost religiously in the desire to attain whiteness [5].

Moving from Asia to Africa, some anthropologists argue that the female ideal of beauty predating colonialism also leaned toward skin tones of a lighter brown hue or those with yellowish or red tints [11], whilst in Latin America skin tone has long been a marker of status [12] and the established ideal of a fairer complexion is reflected by the skin tone of those who continue to occupy positions amongst the upper social ranks.

Interestingly, in Europe and North America the desire for a translucent appearance seems to have come full circle. During the Elizabethan era many women used products containing toxic substances such as ceruse, ammonia and lye to achieve a white complexion [13]. English immigrants exported this partiality for a lighter skin tone to America, adopting new concerning practices in their drive for lightness including arsenic wafer ingestion [14]. In the early 20th century US physicians went as far as using radiotherapy in an attempt to bleach the skin [15]. A pale face was considered a sign of refinement up until the mid-20th century [15]. By the 1940s, however, a tanned complexion became the poster for health and social status [15]. In recent years, however, a heightened sun awareness has seen a return to skin care that incorporates sun protection amongst Caucasian females in the interest of maintaining a more youthful skin appearance.

\section{Colorism: The Financial and Social Currency of Light Skin Privilege}

Beyond our understanding of colour across races, an appreciation of the colour palate within a race group is in itself an exercise in social subtleties. Colorism is the process of distinguishing among same-race individuals on the basis of skin colour stratification [16]. Colorism, which is distinct from and yet inextricably linked to race, is practiced by both whites and people of colour alike [17].

The origins of colorism can be traced back to the early class hierarchies of Asia [18], where lighter skin was associated with the leisure classes, and to the legacy of colonialism across countries such as Vietnam, India and the Philippines [19], and slavery in America [20].

The nomadic Aryan race who conquered India used their lighter skin as a mark of distinction from the local Dravidians, favouring those of a lighter skin tone [21]. The days of slavery in the United States saw lighter-skinned slaves treated more humanely, with a greater likelihood of them being kept to help indoors and in some instances allowed certain opportunities such as being allowed to read [4]. Despite reasoning, past experience continues to colour future expectation and with it our perception of attributes required for success. Today lighter-skinned individuals within the same race group continue to be treated in a more favorable manner as early as their school days [22]. Teachers' expectations of better family backgrounds, behavior, aptitude and academic success lean disproportionately in favour of their lighter-skinned students in comparison to those with darker skin [22]. As expectation is linked closely with outcome, this may be an early advantage leading to heightened opportunities in later life with documented greater completion of school years, higher income potential, housing in better neighborhoods and marriage to more wealthy partners seen amongst lighter-skinned individuals in comparison to darker-skinned individuals [23-25]. 


\section{The Advantages of a Lighter Shade: Motivation behind the Hue}

Despite perceived or constructed differences, women across Asia, Europe and the Mediterranean have incorporated skin-lightening practices into their beauty regimens for many years due to reasons discussed thus far, including the desire to appear more refined and attain greater access to heightened social status and financial security.

Further to this, use in many colonial outposts alluded to an appeal in distancing the user from labourer status and to be purged outwardly from any tinge of association with the darker races [26]. Whilst the largest consumers initially were made up of ambiguously raced individuals, including Jews, the target group multiplied many fold when members of the black community began using these lightening products with a similar intent of social navigation [26].

It may seem tempting to dismiss these beauty motivations to outposts of the past and lesser educated individuals, but current trends indicate these desires continue to permeate more affluent, higher educated, urban females [3,4]. The reasons Ghanaian and Tanzanian women cite for use of skin-lightening agents include the desire for blemish-free skin and to counter the effects of sun exposure, to appear and feel clean, to appear white, European and beautiful, to attract or please a partner and to appear sophisticated and gain social and economic mobility [27]. In a recent study of 600 African and Indian South African women by Dlova et al. [28], 32.7\% reported using skin-lightening products. The main reasons cited were treatment of skin problems (66.7\%) and skin lightening (33.3\%) [28].

\section{The Politicization of Skin Colour}

While colour has been used as a symbol in the social and economic arena, the interpretation of complexion has also been afforded a political agenda. During the period of Pan-Africanism and Black Cultural Nationalist movements, skin tone became a further means of propagating the message for self-acceptance and racial equality [26]. While cultivation of beauty was embraced by many females as a means to social and economic freedom, the practice of migrating toward a preconceived aesthetic ideal was viewed by some as an adoption of physical characteristics that played in to white cultural hegemony [29]. The desire to lighten skin tone was denounced by several New Negro movements as a reflection of an under-developed racial consciousness and viewed as a sign of self-hatred [29].

The legacy of colonialism in Africa, and apartheid in South Africa in particular, has been felt to have imprinted a negative perception of self within the black community [1] where "White is Right" moved from political ideology to segregationist reality [30]. In 1976, Steve Biko, the most prominent black consciousness leader in South Africa, expressed that the black female pursuit to make their "skin as light as possible" proved the motivation for the development of the motto "Black is Beautiful" [31]. By the 1980s medical professionals and Black Consciousness activists collaborated in campaigning for a government ban on skin lighteners in South Africa. Despite this, skin bleaching rates amongst women within the African continent continue to range from 25\% in Mali [32], 35\% in South Africa [1] to $70 \%$ in Nigeria [33].

\section{Advertising and the Market That Fuels the Trade}

Despite political and medical campaigns promoting self-acceptance, strategic, well-funded commercial marketing campaigns continue to hold the majority ransom to the promise of beauty aligned in favour of a fairer complexion. Advertisements convince the consumer that good skin is young, wrinkle-free, bright or lighter, even in complexion and smooth textured. Belief is guaranteed as both philosophies, i.e., the "expertise" and safety of Western products and the "natural philosophy" with ingredients such as turmeric, honey and milk protein, are incorporated, playing to the consumer who favours either science-based modern formulae or a more traditional approach, ensuring an all-encompassing consumer culture [21].

Sociologists and anthropologists document how judgment is coloured by skin tone. Darker-skinned individuals are viewed as less intelligent, attractive and trustworthy than those 
with lighter skin [16,34]. From the preconception of the symbolic capital that skin colour affords to documented research reflecting the stance on the subject by communities at large, we begin to appreciate the lucrative navigation to healthy capital return.

During the 19th century skin-lightening products were targeted mainly at white females in Europe and the United States. The period after World War I saw pale skin become associated with those confined to factory work. A healthy tan was seen as a sign of travel and affluence and use of lightening products dwindled. Manufacturers subsequently shifted their focus to the African American market and later to black communities within Africa itself [2].

Large corporations invested heavily in the development of lightening agents [4]. The largest consumer market is made up of Indians and the diasporic Indian community [35], and corporations have viewed India as an ideal market with its poorly regulated ports, rising economy and the growth of the Indian middle class [36].

From India to other countries across Asia, the skin-lightening industry maintains a strong foothold with a survey in 2007 reporting a $24 \%$ to $47 \%$ usage rate of lighteners in China, Hong Kong, Taiwan, Korea and Japan, with the figure rising to $52 \%$ if financial restriction was removed as a limitation [37].

Skin lighteners surfaced within Africa via two routes: local manufacture and importation [38]. Locally, trade boomed in the Apartheid Era when white businesses strategically pinned business growth potential to heightened trade targeted at the black consumer. In South Africa especially, where the nuance of colour attained political significance, the lightening industry prospered as they played on the desire for basic human rights; a lighter skin tone literally was the key to freedom of movement, a decent education and the right to vote [26]. Toward the end of the 1960s bleaching creams were the fourth most common household product after soap, tea and milk [38].

Presently interest in African and Asian countries has been heightened, as market surveys conducted in 2010 by the beauty and personal care industry reported a double digit growth in the industry in India and other emerging economies (Brazil, Indonesia, Argentina), while the growth rate was much lower in established countries at $4 \%$ [39].

\section{Active Ingredients and Complications of Skin-Lightening Agents}

A diverse range of both synthetically compounded products and naturally occurring or biologic agents are used for skin lightening [40-42]. In many instances multiple products are used concurrently or sequentially with the onset of complications ranging from six to 60 months $[43,44]$.

Skin-lightening ingredients can be classified by their mechanism of action (Table 1):

Table 1. Skin lighteners-Mechanism of action and ingredients.

\begin{tabular}{cc}
\hline Mechanism of Action & Ingredients \\
\hline Chemical Tyrosine inhibitors & Hydroquinone \\
Arbutin \\
Kojic Acid \\
Azelaic Acid \\
Mercury \\
Botanicals \\
\hline Inhibitors of Melanocyte Transfer & Niacinamide \\
\hline Accelerators of epidermal & Vitamin A Derivatives (Retinoids) \\
turnover and desquamation & Vitamin C \\
& Vitamin E \\
\hline Antioxidants & Phytic acid \\
& Ubiquinon \\
& Glutathione \\
\hline Anti-inflammatory & Coenzyme Q-10 \\
\hline
\end{tabular}




\subsection{Tyrosinase Inhibitors}

Tyrosine inhibition is the most widely used and important step targeted by lightening agents. Tyrosinase is an enzyme that catalyzes the production of melanin in the melanocyte. Inhibition can be achieved by the use of chemical and biological compounds [41]. The most widely used tyrosine inhibitors include hydroquinone and its derivatives arbutin and kojic acid [41].

\subsubsection{Hydroquinone}

Hydroquinone is considered the gold standard in the treatment of hyperpigmentation and is a component of many skin-lightening regimens [45]. It may be used safely and effectively under the careful supervision of a dermatologist. Common concentrations employed range between $2 \%$ and $4 \%$. Higher concentrations (up to $7 \%$ in some countries [45]) can be used with greater efficacy and adverse effects are noted. It is a competitive inhibitor of tyrosinase activity. Other properties include oxidation of membrane lipids and proteins through generation of reactive oxygen species with subsequent inhibition of DNA and RNA synthesis within the melanocytes [40].

Common side effects include irritant and allergic contact dermatitis, especially at higher concentrations. The most dangerous side effect noted with chronic use is exogenous ochronosis. First reported in 1906, it is characterized by progressive asymptomatic hyperpigmentation (blue-black), skin coarsening (mild), papule formation within normal skin (moderate), and eventual black caviar-like papulonodules (severe) (Figure 1) [43,44,46] frequently on sun-exposed areas (temples, malar area, cheeks and neck). Ochronosis is characterized histologically by degeneration of elastic and collagen fibres and deposition of ochre-coloured fibres within the dermis.

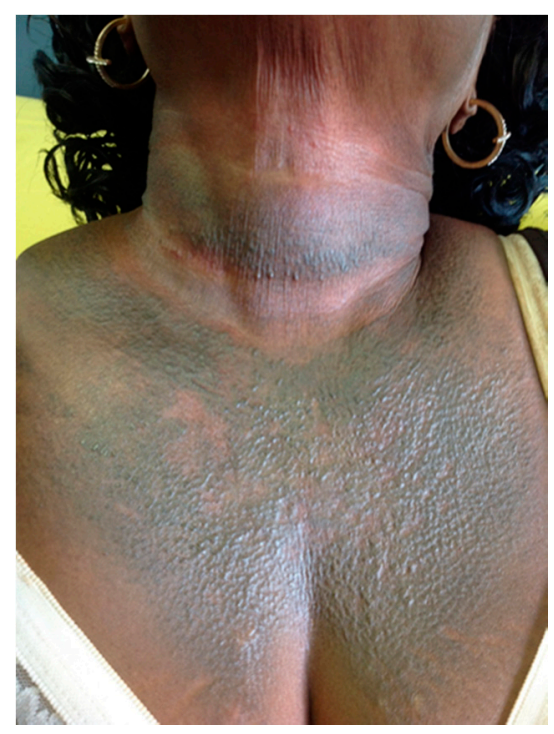

Figure 1. Severe ochronosis in a 48-year-old black female post hydroquinone use.

Comparative studies in South Africa have shown a decline in ochronosis over the past two decades, and this has been attributed to stricter South African government regulations regarding sale and use of hydroquinone-containing skin-lighteners [44,47,48].

Other side effects of hydroquinone use include: permanent depigmentation, loss of skin elasticity, impaired wound healing, cataracts, pigmented colloid milia and scleral and nail pigmentation. Nail pigmentation can extend to all 20 nails assuming a fawn colour and has been referred to as the "pseudo-yellow nail syndrome" [43].

A postulated side effect of chronic hydroquinone use is the development of cutaneous and systemic malignancies $[43,49]$. Case reports have noted the association of hydroquinone (oral) with malignancies in rodents; however, there has been a lack of conclusive evidence supporting carcinogenic 
effects from its topical use. The mechanism of cancer formation is thought to be related to melanin destruction, sun exposure and steroid-induced immunosuppression or via a direct carcinogenic effect of the hydroquinone itself [49].

\subsubsection{Arbutin}

Arbutin is a natural hydroquinone derivative found in dried leaves of different plants. It is a competitive tyrosinase inhibitor, but is less cytotoxic to the melanocytes than hydroquinone. It proves to be more efficacious when compounded in higher concentrations [42]. Higher concentrations, however, carry a greater risk for paradoxical hyperpigmentation [42].

\subsubsection{Kojic Acid}

Kojic acid is a fungal product from the Aspergillus and Acinetobacter family that inhibits tyrosinase production and acts as a potent antioxidant and a free radical scavenger [41,42]. It is often unstable in formulations and may cause irritation and sensitization of the skin.

\subsubsection{Azelaic Acid}

Azelaic acid is a compound found in wheat, rye and barley [40,41]. It is naturally produced by the yeast pityrosporum ovale. It acts via inhibition of tyrosinase and melanocyte proliferation as well as by suppressing reactive oxygen species. Common side effects are irritation, pruritus and erythema [41].

\subsubsection{Mercury}

Mercury or mercury salts cause skin depigmentation through inhibition of melanin formation [46]. The mercaptans compete with the copper in tyrosinase, leading to inactivation of tyrosinase activity.

The side effects of mercury are related to its absorption as vapor or topical absorption through the skin, the gastrointestinal tract as well as its excretion via the kidney and colon. On the skin, the side effects include paradoxical hyperpigmentation, discolouration and fragility of the nails [43,46].

Mercury toxicity following cutaneous absorption can result in systemic complications. Acutely, mercury toxicity may cause gastric discomfort and acute pneumonitis. Chronic complications in the kidney can result in nephrotic syndrome and glomerulonephritis (both membranous and proliferative) [43]. These side effects have led to the banning of mercury compounds in most countries. Illegal inclusion and product mislabeling, however, continue to be noted in bleaching creams [47].

\subsection{Inhibitors of Melanocyte Transfer}

The transfer of melanosomes into keratinocytes is an important step in skin pigmentation. This step involves interaction between melanocytes and keratinocytes via dendritic processes and expressor proteins within membranes of both cells $[40,41]$.

\section{Niacinamide}

Niacinamide, the active form of niacin (vitamin B3), has antioxidant activity interfering with the interaction between and transfer of melanosomes from melanocytes to keratinocytes. It has been shown to reduce the total area of hyperpigmentation and increase brightness within four weeks of treatment initiation $[41,42]$.

\subsection{Accelerators of Epidermal Turnover and Desquamation}

\subsubsection{Vitamin A Derivatives (Retinoids)}

Vitamin A derivatives increase cell turnover, inhibit tyrosinase activity, interfere with pigment transfer to keratinocytes and cause keratinocyte pigment granule dispersion. Over longer periods of use, retinoids cause increase stratum corneum compaction and decrease melanin content [42]. 
They may be used in combination with hydroquinone and or steroids, thereby reducing atrophy caused by topical steroids and facilitating better epidermal penetration and delivery of hydroquinone [41,42]. Adverse effects of retinoid use are erythema and skin desquamation [41]. The irritant reaction can cause paradoxical hyperpigmentation [42].

\subsubsection{Alpha and Beta Hydroxyl Acid and Derivatives}

Alpha hydroxyl acids act via desquamation and tyrosinase inhibition without interfering with RNA synthesis and protein expression.

Glycolic, lactic, salicylic, citric acid preparations and their derivatives are most widely used in cosmetic preparations as peeling agents, with shedding of the stratum corneum improving skin colour and tone [41]. Combination with other skin-lightening agents usually improves efficacy. Adverse effects include burning and erythema [41].

\subsection{Antioxidants}

Antioxidants are thought to reduce oxidation of tyrosine to dihydroxyphenylalalanine quinone and to reduce free radical injury to keratinocytes caused by ultraviolet exposure.

Vitamin C is photoprotective as it deactivates UV-induced free radicals. It is also a tyrosinase inhibitor and acts as a reducing agent at various oxidative steps of melanin formation. Topical vitamin $\mathrm{C}$ from natural sources is unstable and the more stable ascorbic acid derivatives are, therefore, used in the forms of magnesium ascorbyl phosphate (MAP) and sodium ascorbyl phosphate (SAP). MAP is also better absorbed in the stratum corneum, as it is lipophilic [42].

Vitamin E, a lipid soluble antioxidant, causes depigmentation by inhibiting tyrosinase, through lipid peroxidation of melanocyte membranes and by increasing intracellular glutathione content [42].

Heightened skin-lightening efficacy may be seen with concomitant vitamin $\mathrm{C}$ and vitamin $\mathrm{E}$ use [41].

Other antioxidant agents include glutathione, phytic acid and ubiquinone [41]. Glutathione is currently trending as a skin-lightening agent [50]. It is available and used in topical, oral and intravenous preparations [50]; however, there are currently few studies that have looked at its efficacy and its adverse effects, especially in its intravenous forms [42]. Therefore, more studies are required to determine and validate the use and safety of this antioxidant as a skin-lightening agent [42].

Antioxidants have further been promoted for their proposed anti-aging benefits. The use of coenzyme Q-10 topically in various cosmetic agents must be highlighted as the hydrogen peroxide generated as part of their metabolism may further upset the oxidative stress in individuals predisposed to developing vitiligo with Q-10 having been documented as a trigger for vitiligo [51].

\subsection{Anti-Inflammatories}

\section{Corticosteroids}

Corticosteroids have been used extensively as depigmenting agents with over-the-counter preparations being readily available [43]. A study conducted in Nigeria revealed that the potent topical corticosteroids fluocinonide, betamethasone dipropionate and clobetasol propionate were the most commonly used agents [43]. Depigmentation of the skin following topical steroid use is thought to be related to vasoconstriction. Chronic use leads to the inhibition of epidermal melanogenesis [43,46]. Adverse effects associated with chronic use include hypopigmentation, hypertrichosis, steroid-induced rosacea, striae (Figure 2), skin atrophy, tinea (Figure 2), acne (Figure 3) and telangiectasia (Figure 3). Systemic side effects include Cushing's syndrome, hypertension, diabetes mellitus, adrenal insufficiency and immunosuppression [46]. 


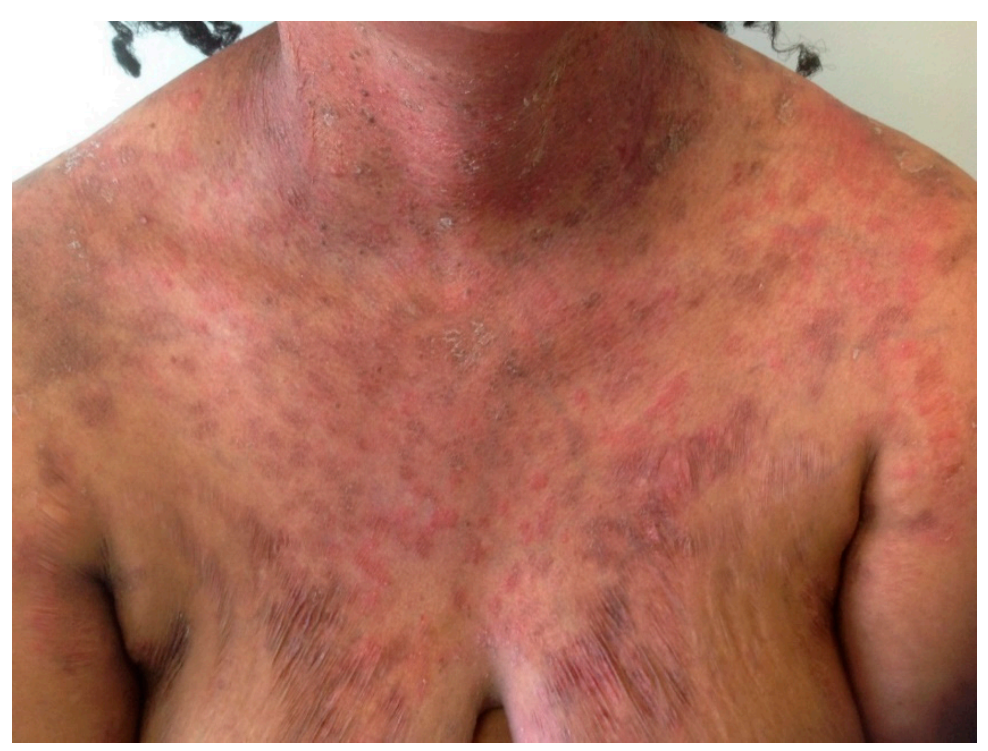

Figure 2. Topical corticosteroid-induced striae and tinea incognito.

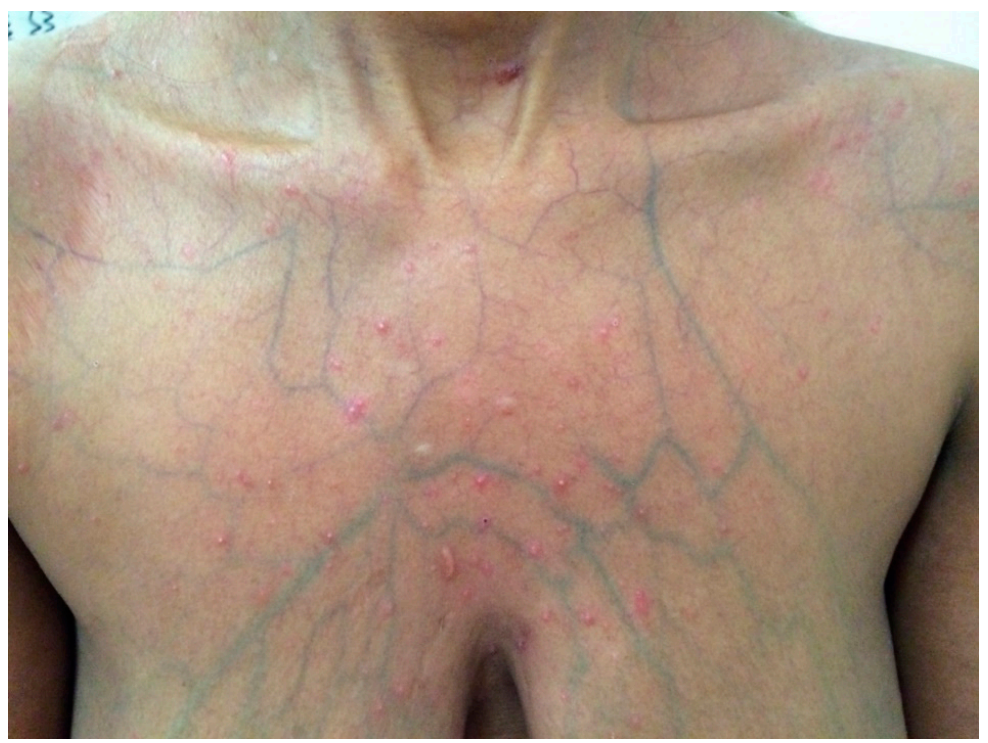

Figure 3. Topical-induced skin atrophy, telangiectasia and acne.

\subsection{Botanicals and New Approaches to Skin Lighteners}

Topical botanical extracts are becoming increasingly popular as alternative therapies in skin lightening regimes [52]. Their modes of action include tyrosinase inhibition, anti-inflammatory action, antioxidant activity and melanin dispersion [40-42,52]. The most commonly used botanical extracts include soy, licorice extract, coffee berry, mulberry extracts and green tea [52].

They are safe, more affordable, exhibit fewer side effects, are available over the counter and are, therefore, now being used as active ingredients in many cosmeceuticals [52]. Caution must, however, be exercised, as case reports of adulterated botanical creams have been noted [52].

\section{The Regulation of Skin Lighteners}

The growing number of skin-lightening agents raises concern for increased cutaneous and systemic adverse events. Strict regulation of these items is, therefore, mandatory and an important public health concern. Several African countries, including South Africa, Ghana, Tanzania and Zambia, 
have legislated bans against the manufacture, import and over-the-counter sales of certain bleaching products which contain hydroquinone, mercury, phenol and resorcinol [1,53]. Even in countries with adequate legislation, however, enforcement of these laws remains suboptimal, with Africa remaining a destination point for many bleaching agents with dangerously high concentrations, from manufacturers in Asia and Europe [29].

Concerns over mercury in lightening agents were first put forward by dermatologists who began observing a darker pigmentation at sites of mercury application and oxidation as well as nephrotoxicity [54]. Mercury use was banned from cosmetic products in the United States and South Africa in the 1970s [26].

Manufactures of bleaching agents retorted by changing their principal ingredient to hydroquinone with the subsequent surfacing of concerns over the increased prevalence of exogenous ochronosis, particularly with prolonged use at high concentrations in areas of high ultraviolet ray exposure without proper sun protective measures [55].

Medical allies in South Africa and Black Consciousness Activists joined forces and in 1982 were successful in getting the South African government to regulate the use of hydroquinone over-the-counter product content to the $2 \%$ concentration permitted in the United States [56].

In 1988 the South African government finally bowed to pressure of warnings from the National Black Consumer Union and The Dermatological Society of South Africa and passed a law banning the use of hydroquinone from cosmetics [57] with similar restrictions subsequently enforced elsewhere.

A heightened public awareness of the dangers skin lighteners pose is imperative. This group of agents is frequently considered as 'cosmetic' and their potential for harming an individual's health is often underappreciated. An informed public may support an expedited development and enforcement regarding the availability and use of skin lighteners, affording a greater protective benefit.

\section{Conclusions}

The multiple motivations behind skin-lightening may be as varied as the spectrum of skin tones displayed across races, cultures and geographic shores. The mindset cultivated in a culture coloured by current beliefs regarding skin tone may presently be more receptive to advice detailing safer lightening practices than an avoidance of the practice altogether. Two areas for further research include the short-term development of safe, cost-effective and stable skin-lightening agents with evidence-based clinical data outlining efficacy and safety profiles and the long-term development of health, behavioural and health-promotional studies to increase awareness of the psychology behind complexion and the creation of health models to promote a more receptive adoption of an individual's natural skin tone. It is with the latter goal in mind that dermatologists may be able to more meaningfully persuade away from the current constructs of a lighter aesthetic ideal and look toward promoting and maintaining healthier skin.

Author Contributions: Levashni Naidoo conceptualized and wrote the majority of the original draft of the paper and reviewed and approved the final version of the paper. Nokubonga Khoza contributed to the write up and approved final version of the paper. Ncoza C. Dlova conceptualized and, critically appraised, reviewed and approved the final version of the paper.

Conflicts of Interest: The authors declare no conflicts of interest.

\section{References}

1. Blay, A. Skin Bleaching and Global White Supremacy: By Way of Introduction. J. Pan Afr. Stud. 2011, 4, 4-46.

2. Peiss, K. Hope in a Jar: The Making of America's Beauty Culture; University of Pennsylvania Press: Philadelphia, PA, USA, 2011.

3. Ntshingila, F. Female Buppies Using Harmful Skin Lighteners. Sunday Times, 27 November 2005.

4. Glenn, E.N. Yearning for Lightness; Transitional Circuits in the Marketing and Consuption of Skin Lighteners. Gend. Soc. 2008, 22, 281-302. [CrossRef] 
5. Li, E.P.; Min, H.J.; Belk, R.W. Skin lightening and beauty in four Asian cultures. NA-Adv. Consum. Res. 2008, $35,444-449$.

6. Arif, H. Woman's Body as a Culture Measurung Text: A Signification of Bengali Culture. Semiotica 2004, 150, 579-595.

7. Jeon, W. The Cultural History of Make-Up in Korea; Yeolhwadang Publishing Company: Seoul, Korea, 1987.

8. Ashikari, M. The Memory of the Women's White Faces: Japanseness and the Ideal Image of a Women. Jpn. Forum 2003, 15, 55-79. [CrossRef]

9. Ashikari, M. Urban Middle Class Japanese Women and Their White Faces: Gender, Ideology, and Representation. Ethos 2003, 31, 3-37. [CrossRef]

10. Some Are Prepared to go Beyond the Pale. China Daily. 25 May 2006. Available online: http://www. chinadaily.com.cn/cndy/2006-05/25/content_599571.htm (accessed on 27 February 2016).

11. Burke, T.D. Lifebouy Men, Lux Women: Commodification, Consumption and Cleanliness in Modern Zimbabwe; Duke University Press: Durham, NC, USA, 1996.

12. Stepen, N.L. The Hour of Eugenics: Race, Gender and Nation in Latin America; Cornell University Press: Ithaca, NY, USA, 1991.

13. Neville, W. Powder and Paint: A History of the English Women's Toilet_Elizabeth I to Elizabeth II; Longmans: London, UK, 1957.

14. Brownmiller, S. Femininity; Schuster Sa: New York, NY, USA, 1984.

15. Can the Ethiopian change his skin or the leopard change his spots: Radium light turns Negro's skin white. Boston Globe, 25 January 1904.

16. Hunter, M. Race, Gender and the Politics of Skin Tone; Routledge: New York, NY, USA, 2005.

17. Hunter, M. The persistent Problem of Colorism: Skin Tone, Status and Inequality. Sociol. Compass 2007, 1, 237-254. [CrossRef]

18. Rondilla, J.; Spickard, P. Is Lighter Better? Skin The Discriimination amongst Asian Americans; Rowman \& Littlefield Publishers: Lanham, MD, USA, 2007.

19. Jordan, W. White over Black: American Attitudes toward the Negro, 1550-1812; UNC Press: Chapel Hill, NC, USA, 1968.

20. Stevenson, B.E. Life in Black and White: Family and Community in the Slave South; Oxford University Press: Oxford, UK, 1996.

21. Johnson, S.E. The Pot Clling TheKettle Black? Gender-Specific Health Dimensions of Colour Prejudice in India. J. Health Manag. 2002, 4, 215-227. [CrossRef]

22. Murguia, E.; Telles, E. Phenotype and Schooling among Mexican Americans. Sociol. Educ. 1996, 69, 97-102. [CrossRef]

23. Arce, C.H.; Murguia, E.; Frisbie, W.P. Phenotype and life chances among Chicanos. Hisp. J. Behav. Sci. 1987, 9, 19-32.

24. Hill, M.E. Colour Difference in the Socioeconomic Statuses of Africn American Men: Results of a Longitudinal Study. Soc. Forces 2000, 78, 1437-1460. [CrossRef]

25. Hughes, M.; Hertel, B.R. The Significance of Colour Remains: A Study of Life Chance, Mate Selection and Ethnic Consciousnes among Black Americans. Soc. Forces 1990, 68, 1105-1120. [CrossRef]

26. Thomas, L.M. Skin Lighteners, Black Consumers and Jewish Entrepreneurs in South Africa. Hist. Workshop J. 2012, 73, 259-283. [CrossRef] [PubMed]

27. Blay, Y.A. Yellow Fever: Skin Bleaching and the Politics of Skin Color in Ghana. Ph.D. Thesis, Temple University, Philadelphia, PA, USA, 2007.

28. Dlova, N.C.; Hamed, S.H.; Tsoka-Gwegweni, J.; Grobler, A. Skin lightening practices: An epidemiological study of South African women of African and Indian ancestries. Br. J. Dermatol. 2015, 173, 2-9. [CrossRef] [PubMed]

29. Lindsey, T.B. The Formalization of White Cultural Hegemony in African American Beauty Culture. J. Pan Afr. Stud. 2011, 4, 103-116.

30. Nahomie, J. Skin Bleaching in South Africa: Result of Colonialism and Apartheid? Discov. Ga. State Honours Coll. Undergrad. Res. J. 2014, 2, 4.

31. Biko, S. I Write What I Like: A Selection of His Writings; Harper \& Row: New York, NY, USA, 1978; p. 104.

32. Souza, M. The concept of skin bleaching in Africa and its devastating health implications. Clin. Dermatol. 2008, 26, 27-29. [CrossRef] [PubMed] 
33. Pitche, P. Cosmetic Use of Skin Bleaching Products and associated complications. Int. J. Dermatol. 2005, 44, 39-40. [CrossRef] [PubMed]

34. Herring, C.; Keith, V.; Horton, H.D. Skin Deep: How Race and Complexion Matter in the "Color Blind" Era; University of Illinois Press: Champaign, IL, USA, 2004.

35. Webb, S.L. The Epidemic of Skin Bleaching Around the World. Available online: http://colorismhealing. org/skin-bleaching-around-world/ (accessed on 27 February 2016).

36. Runkle, S. Making 'Miss India': Constructing gender, power and nation in Post Liberalisation India. South Asian Pop. Cult. 2004, 2, 145-159. [CrossRef]

37. Nielson. Health, Beauty and Personal Grooming: A global Nielson Consumer Report. Available online: https:/ / www.yumpu.com/en/document/view/602134/health-beauty-amp-personal-groomingnielsen (accessed on 27 February 2016).

38. The Urban Bantu Market: Understanding it Complexities and Developing its Potential. In Proceedings of a 2-Day Seminar, Durban, Natal (The National Development and Management Foundation, Johannesburg, South Africa), February 1969.

39. Euromonitor, I. Beauty and Personal Care 2011: Corporate Strategies in and beyond the BRICS; Euromonitor International: London, UK, 2012.

40. Gillbro, J.M. The melanogenesis and mechanisms of skin lightening agents-Existing and new approaches. Int. J. Cosmet. Sci. 2011, 33, 210-221. [CrossRef] [PubMed]

41. Kamakshi, R. Fairness via formulations: A review of cosmetic skin-lightening ingredients. J. Cosmet. Sci. 2012, 63, 43-54. [PubMed]

42. Sarkar, R.; Arora, P.; Garg, K.V. Cosmeceuticals for Hyperpigmentation; what is available? J. Cutan. Aesthet. Surg. 2013, 6, 4-11. [CrossRef] [PubMed]

43. Yetunde, M.; Olumide, M.; Ayesha, O. Akinkugbe Complications of chronic use of skin lightening cosmetics. Int. J. Dermatol. 2008, 47, 344-353.

44. Dlova, N.C.; Hendricks, N.E. Skin lightening creams used in Durban, South Africa. Int. J. Dermatol. 2012, 51, 51-53. [CrossRef] [PubMed]

45. Mahé, A.; Ly, F.; Aymard, G.; Dangou, J.M. Skin diseases associated with the cosmetic use of bleaching products in women from Dakar, Senegal. Br. J. Dermatol. 2003, 148, 493-500. [CrossRef] [PubMed]

46. Dadzie, O.; Petit, A. Skin bleaching: Highlighting the misuse of cutaneous depigmenting agents. J. Eur. Acad. Dermatol. Venereol. 2009, 23, 741-750. [CrossRef] [PubMed]

47. Dlova, N.C.; Ajose, F. Communication on the dangers and abuse of skin lighteners in Africa. Int. J. Dermatol. 2014, 53, 335-337. [CrossRef] [PubMed]

48. Dlova, N.C.; Mankahla, A. The spectrum of skin diseases in a black population in Durban, Kwazulu-Natal, South Africa. Int. J. Dermatol. 2015, 54, 279-285. [CrossRef] [PubMed]

49. Ly, F.; Kane, A. First cases of squamous cell carcinoma associated with cosmetic use of bleaching compounds. Ann. Dermatol. Venereol. 2010, 137, 128-131. [CrossRef] [PubMed]

50. Sarkar Arora, P.; Vijay Garg, K. Glutathione as a skin whitening agent: Fact, myths, evidence and controversies. Indian J. Dermatol. Venereol. Leprol. 2016, 82, 262-272.

51. Schallreuter, K.U. Q10-triggered facial vitiligo. Br. J. Dermatol. 2013, 169, 1333-1336. [CrossRef] [PubMed]

52. Fisk, W.A.; Agbai, O.; Lev-Tov, H.A.; Sivamani, R.K. The use of botanically derived agents for hyperpigmentation: A systematic review. J. Am. Acad. Dermatol. 2014, 70, 352-365. [CrossRef] [PubMed]

53. Dooley, E. Sickening Soap Trade. Environ. Health Perspect. 2001, 109, 469. [CrossRef]

54. Nealon, D. Ammoniated Mecury and the Skin. Drug Cosmet. Ind. 1943, 52, 159.

55. Findlay, G.H.; de Beer, H.A. Chronic Hydroquinone Poisoning of the Skin from Skin Lightening Cosmetics: Aouth African Epidemic of Ochronosis of the Facein Dark-Skinnned Individuals. South Afr. Med. J. 1980, 57, 187-190.

56. Regulations Governing the Sale of Cosmetics Containing Hydroquinone, Mercury, and Lead. S. Afr. Gov. Gazette 1983, 219, 7-9.

57. Tatham, J. Foodstuffs, Cosmetics and Disinfectants Act. Banning of Skin Lighteners, 16 March 1988.

(c) 2016 by the authors; licensee MDPI, Basel, Switzerland. This article is an open access article distributed under the terms and conditions of the Creative Commons Attribution (CC-BY) license (http://creativecommons.org/licenses/by/4.0/). 